\title{
REVIEW
}

\section{A Review of Clinical Practice Guidelines for the Management of Hypertriglyceridemia: A Focus on High Dose Omega-3 Fatty Acids}

Dean G. Karalis

Received: October 24, 2016/Published online: December 15, 2016

(c) The Author(s) 2016. This article is published with open access at Springerlink.com

\section{ABSTRACT}

Cardiovascular (CV) disease remains the leading cause of preventable death in the US. Hyperlipidemia is a major modifiable risk factor for $\mathrm{CV}$ disease, and after numerous clinical trials have demonstrated that reductions in low-density lipoprotein (LDL) cholesterol with statin therapy can prevent major adverse CV events, statins have emerged as the drug of choice to lower LDL cholesterol and reduce $\mathrm{CV}$ risk. However, some statin-treated patients remain at high residual risk of $\mathrm{CV}$ events despite achieving low LDL cholesterol levels, especially if their triglyceride (TG) levels are elevated or their high-density lipoprotein (HDL) cholesterol levels low. Evidence from genetic and observational studies has linked elevated TG levels to an increased risk of CV events. Furthermore, very high TG levels are associated with acute

Enhanced content To view enhanced content for this article go to http://www.medengine.com/Redeem/ 3337F060338C4EDB.

D. G. Karalis ( $\square)$

Perelman School of Medicine, University of

Pennsylvania, Philadelphia, PA, USA

e-mail: dean.karalis@uphs.upenn.edu pancreatitis. Consequently, several clinical practice guidelines provide recommendations for the management and treatment of high and very high TG levels. This review focuses on the clinical practice guidelines for the management of hypertriglyceridemia and the role of prescription omega-3 fatty acids in preventing pancreatitis and $\mathrm{CV}$ disease in individuals with high and very high TG levels.

Keywords: Coronary artery disease; Hypertriglyceridemia; Omega-3 fatty acids; Pancreatitis

\section{INTRODUCTION}

Cardiovascular $(\mathrm{CV})$ disease is the leading cause of preventable death in the US [1]. Hyperlipidemia is a major risk factor for $\mathrm{CV}$ disease, and treating elevated cholesterol has emerged as an important means to prevent $\mathrm{CV}$ events. For the past few decades, the target of lipid-lowering therapy has been low-density lipoprotein (LDL) cholesterol, and numerous large clinical studies in both primary and secondary prevention settings have 
demonstrated a significant reduction in $\mathrm{CV}$ events in patients treated with statin therapy [2-4]. A meta-analysis of data from 170,000 patients in 26 randomized studies reported that for every $38.7 \mathrm{mg} / \mathrm{dL}(1 \mathrm{mmol} / \mathrm{L})$ reduction in LDL cholesterol, major vascular events were reduced by $22 \%$ over a 5 -year period compared with placebo [4].

Statins have now become the established drug of choice to lower LDL cholesterol [5-7]. Despite the benefits seen with statin therapy, some patients, even if they achieve low LDL cholesterol levels, remain at high residual $\mathrm{CV}$ risk, especially if levels of triglycerides (TG) are elevated or high-density lipoprotein (HDL) cholesterol levels low [8, 9]. In the recent IMproved Reduction of Outcomes: Vytorin Efficacy International Trial (IMPROVE-IT), one-third of patients randomized to a combination of simvastatin and ezetimibe suffered a major CV event after a median follow-up of 6 years. This was despite achieving a low LDL cholesterol level of $54 \mathrm{mg} / \mathrm{dL}$ with combination lipid-lowering therapy [10]. The high residual $\mathrm{CV}$ risk in patients treated with statin therapy who achieve low levels of LDL cholesterol may be due to other risk factors beyond LDL cholesterol, including elevated TG, low levels of HDL cholesterol, or the presence of other non-lipid risk factors such as diabetes, metabolic syndrome, uncontrolled hypertension, or cigarette smoking.

Evidence from genetic and observational studies has linked high TG levels to an increased risk of $\mathrm{CV}$ events. Guidelines from several national and international medical organizations provide recommendations for the management and treatment of high and very high TG levels, and in addition to lifestyle changes, these guidelines recommend the use of fibrates, niacin, or high dose omega-3 fatty acids to lower
TG when the levels are very high $[5,6,11-14]$. However, many physicians are not familiar with the clinical practice guidelines for the management of hypertriglyceridemia [15]. Furthermore, citing a lack of effectiveness in CV outcome trials, the Food and Drug Administration (FDA) recently withdrew approval for extended-release niacin and certain fenofibric acid formulations when prescribed in addition to statins to treat high cholesterol [16]. Because many patients with high TG are also on statins, this may lead to less use of these medications and an increased use of high-dose omega-3 fatty acids to treat very high TG. For this reason, it is important for clinicians to be familiar with the clinical practice guidelines for the management of hypertriglyceridemia, and this review focuses on these clinical guidelines and the role of prescription omega-3 fatty acids in preventing pancreatitis and CV disease in individuals with high and very high TG levels.

This article is based on previously conducted studies and does not involve any new studies of human or animal subjects performed by any of the authors.

\section{Prevalence of hypertriglyceridemia}

Hypertriglyceridemia is increasingly common in the US. An analysis of data from the National Health and Nutrition Examination Survey (NHANES) has revealed that the age-adjusted mean LDL-C has fallen significantly over the past few decades, which is most likely related to the increased use of statins [17]. In contrast, over the same time period, there was a significant increase in TG levels [17]. This is likely related to the rise in obesity also seen during the same period [18].

According to the most recent guidelines from the American Heart Association (AHA), TG levels 
are considered normal if they are $<150 \mathrm{mg} / \mathrm{L}$, borderline high if they are 150-199 mg/dL, high if they are $200-499 \mathrm{mg} / \mathrm{dL}$, and very high if they are $\geq 500 \mathrm{mg} / \mathrm{dL}$ [11]. Data from NHANES show that from 2001 to $200632 \%$ of the US adult population had a TG level $\geq 150 \mathrm{mg} / \mathrm{dL}$. Overall, $14 \%$ had borderline-high TG levels, 16\% had high TG levels, and approximately $2 \%$ had very high TG levels [19]. Based on current estimates of the US adult population, this corresponds to over 34 million individuals with borderline-high TG levels, over 39 million individuals with high TG levels, and over 4 million individuals with very high TG levels. NHANES data also show a difference in the prevalence of hypertriglyceridemia (defined as TG levels $\geq 150$ $\mathrm{mg} / \mathrm{dL}$ ) between men and women (29\% and $22 \%$, respectively) and also between age groups [20]. The prevalence of hypertriglyceridemia in women increases steadily with age (15\% in those aged 20-39 years, $23 \%$ in those aged $40-59$ years, and $32 \%$ in those aged $\geq 60$ years), while the prevalence of hypertriglyceridemia in men increases up to middle age and then appears to decrease (25\% in those aged $20-39$ years, $35 \%$ in those aged $40-59$ years, and $25 \%$ in those aged $\geq 60$ years) [20]. There is also a difference in the prevalence of hypertriglyceridemia among ethnicities. The most recent NHANES data reveal that Mexican Americans have a higher prevalence of hypertriglyceridemia compared with non-Hispanic whites or non-Hispanic blacks [20]. This may be due to genetic reasons. For example, it has been found that levels of lipoprotein lipase, an enzyme involved in the hydrolysis of TG from chylomicrons, and very-low-density lipoprotein (VLDL) cholesterol are much higher in African Americans than whites; this results in lower levels of TG in African American patients [21]. Conversely, Asian Indians tend to have high TG levels, which are thought to be due to a mutation in the APOC3 gene, resulting in reduced clearance of TG from the plasma [22].

Lifestyle and disease states can also influence the development of hypertriglyceridemia. The prevalence of hypertriglyceridemia varies considerably between individuals who are obese and overweight and those who are of normal weight. NHANES data for the period 2009-2012 show that 39\% of obese men and $32 \%$ of obese women have elevated TG $(\geq 150 \mathrm{mg} / \mathrm{dL}) \quad$ compared with $28 \%$ of overweight men and $23 \%$ of overweight women and $15 \%$ of normal-weight men and $9 \%$ of normal-weight women [20]. Hypertriglyceridemia is also common in patients with the metabolic syndrome, type 2 diabetes, and renal disease. Approximately 35\% of patients with type 2 diabetes have TG levels $\geq 200 \mathrm{mg} / \mathrm{dL}$ [23], and between $40 \%$ and $60 \%$ of patients with chronic kidney disease have TG levels $\geq 200 \mathrm{mg} / \mathrm{dL}$ [23]. Furthermore, patients with nephrotic syndrome and those on peritoneal dialysis have higher TG levels compared with those patients without nephrotic syndrome or on hemodialysis [24].

\section{Hypertriglyceridemia and the risk of pancreatitis}

Acute pancreatitis is a well-established complication of hypertriglyceridemia but may not be diagnosed in a timely manner as other conditions can cause similar symptoms. If not appropriately diagnosed and managed, pancreatitis can result in repeated hospitalizations and significant physical, psychological, and financial burden $[25,26]$. Hypertriglyceridemia is the third most common cause of pancreatitis after alcohol and gallstones and is found to be the cause of pancreatitis in up to $4 \%$ of cases. It has been 
reported that the incidence of pancreatitis is increasing, perhaps due to changes in diet and lifestyle [25]. The risk of acute pancreatitis increases in a direct relationship to the level of TG. In a retrospective cohort study, after adjusting for covariates and excluding patients with other causes for pancreatitis, the risk of acute pancreatitis increased by $4 \%$ for every $100 \mathrm{mg} / \mathrm{dL}$ increase in TG [27]. Among patients with severe hypertriglyceridemia, the risk of pancreatitis is high. In another retrospective study, $20 \%$ of patients with severe hypertriglyceridemia (defined as TG levels $>1000 \mathrm{mg} / \mathrm{dL}$ ) experienced at least one attack of acute pancreatitis [28]. As TG levels fall rapidly within the first few days of presentation of acute pancreatitis, it is important to measure TG levels upon admission in any patient with acute pancreatitis to avoid missing hypertriglyceridemia as the cause. In addition, mild to moderate hypertriglyceridemia may occur in pancreatitis due to other causes [29]. In general, acute pancreatitis due to hypertriglyceridemia typically occurs when TG levels are $>1000 \mathrm{mg} / \mathrm{dL}[13,25]$.

Although the exact role of hypertriglyceridemia in the etiology of pancreatitis is not fully known, it is thought that the associated increase of chylomicrons causes hyperviscosity, which can lead to ischemia and acidosis in pancreatic capillaries. This in turn causes release of pancreatic lipases, increased lipolysis, and the release of toxic free fatty acids, which cause cytotoxic injury, inflammation, and eventually pancreatitis $[26,31]$.

\section{Hypertriglyceridemia and the risk of cardiovascular disease}

Whether TG causes CV disease has been the subject of considerable debate. In part, this is related to the observation that some patients with very high TG levels are not at risk of $\mathrm{CV}$ disease, whereas other patients with only mild-to-moderate TG elevations are at increased $\mathrm{CV}$ risk. This paradox can be explained by the fact that in patients with TG $>1000 \mathrm{mg} / \mathrm{dL}$, the predominant TG lipoproteins are chylomicrons, which are too large to penetrate the intimal surface and cause atherosclerosis [10]. In contrast, in patients with mild-to-moderate TG elevations, the predominant TG-rich lipoproteins are VLDL and intermediate-density lipoprotein (IDL), whose remnants are small enough to penetrate the intimal surface and lead to atherosclerosis. Therefore, it is individuals with mild-to-moderate TG elevations who are at particularly high risk of CV disease.

Observational, randomized clinical, and genetic studies all support the causal relationship between TG and CV disease. For example, large population studies such as the Copenhagen City Heart Study suggest that increasing levels of non-fasting TG are associated with increasing risk of myocardial infarction, ischemic heart disease, ischemic stroke, and death in adults [32, 33]. Furthermore, the Emerging Risk Factors Collaboration analyzed more than 300,000 individuals from 68 long-term prospective studies and found that elevated levels of fasting and non-fasting TG were associated with an increased risk of coronary heart disease after adjusting for non-lipid risk factors [34]. This risk was attenuated after adjusting for non-HDL cholesterol levels, which suggests that it is the cholesterol within TG-rich remnant lipoproteins that is the cause of coronary heart disease rather than the increase in TG themselves. Other studies have shown that the $\mathrm{CV}$ risk associated with TG is attenuated when adjusting for HDL cholesterol [35]. Low levels of 
HDL cholesterol are commonly associated with hypertriglyceridemia. TG levels can vary widely on a daily basis, while levels of HDL cholesterol are less variable; therefore, low HDL cholesterol may be a marker for the presence of TG-rich remnant lipoproteins, which may explain why it is more strongly associated with $\mathrm{CV}$ disease than TG [36].

Despite the increasing use of statins, and the subsequent reduction in LDL cholesterol, some statin-treated patients remain at risk of $\mathrm{CV}$ disease in part because of elevated TG levels. In a pooled analysis of two large clinical outcomes studies with statin therapy, the Treating to New Targets (TNT) and Incremental Decrease in End Points through Aggressive Lipid Lowering (IDEAL) studies, the $\mathrm{CV}$ risk was higher in patients with on-treatment $\mathrm{TG} \geq 150 \mathrm{mg} / \mathrm{dL}$ than in those with TG $<150 \mathrm{mg} / \mathrm{dL}$ [8]. After adjusting for age and sex, the risk of a CV event increased across the quintiles of TG. Patients in the highest quintile of TG levels had a 63\% higher CV event rate than those in the lowest quintile, despite having achieved low LDL cholesterol levels with statin therapy. The average LDL cholesterol level in IDEAL was $91 \mathrm{mg} / \mathrm{dL}$ and $87 \mathrm{mg} / \mathrm{dL}$ in TNT. In an analysis of patients with acute coronary syndromes from the dal-OUTCOMES study and the atorvastatin arm of the Myocardial Ischemia Reduction with Acute Cholesterol Lowering (MIRACL) study, it was found that the higher the on-treatment TG level, the higher the CV risk [37]. The long-term $\mathrm{CV}$ risk was two-fold higher in patients with TG $>175 \mathrm{mg} / \mathrm{dL}$ compared with those with TG $<100 \mathrm{mg} / \mathrm{dL}$. The increased CV risk associated with elevated levels of TG occurred on the background of effective statin therapy. The median LDL cholesterol level achieved in the dal-OUTCOMES study was $73 \mathrm{mg} / \mathrm{dL}$, and approximately $97 \%$ of patients were taking a statin. The risk associated with increasing TG levels remained significant and was not attenuated after adjusting for other risk factors, including HDL and LDL cholesterol levels.

Mendelian randomization studies have provided further evidence linking TG and CV disease. In a large Mendelian randomization study, heterozygotes for a single APOA5 genetic variant had a $16 \%$ higher mean TG level, and homozygotes had a 33\% higher mean TG level than non-carriers [38]. The risk of coronary heart disease increased in a dose-dependent manner, with an approximately $18 \%$ higher CV risk for each variant allele inherited. In another large Mendelian randomization study, a total of 73,513 subjects from Copenhagen were genotyped and 15 genetic variants were selected that affected non-fasting remnant cholesterol, HDL cholesterol, or both [39]. The term remnant cholesterol refers to the cholesterol carried on TG-rich lipoproteins including chylomicrons remnants, VLDL, and intermediate-density lipoproteins (IDL) and in this study was calculated by subtracting HDL and LDL cholesterol from total cholesterol. A non-fasting remnant cholesterol increase of $39 \mathrm{mg} / \mathrm{dL}$ was associated with a 2.8-times increased risk for ischemic heart disease, independent of low levels of HDL cholesterol. Genome-wide association studies have also provided evidence of the causal relationship between TG and CV disease. Two studies showed that loss-of-function mutations in APOC3 were associated with lower levels of TG and a reduced risk of ischemic heart and vascular disease $[40,41]$. Taken together, these genetic, clinical, and population studies support a strong causal relationship between high concentrations of TG-rich lipoproteins or remnant cholesterol and CV disease. 
TGs are predominantly carried in the circulation by chylomicrons and VLDL particles. These lipoprotein particles undergo remodeling via the actions of lipoprotein lipase and other lipases, which leads to the formation of remnant particles, often termed TG-rich remnant lipoproteins. Remnant particles include chylomicron remnants as well as VLDL and IDL particles. Non-HDL cholesterol is a measure of the cholesterol content of these TG-rich remnant lipoproteins and is defined as total cholesterol minus HDL cholesterol. When TG levels are $\geq 1000 \mathrm{mg} / \mathrm{dL}$, the predominant particles carrying TG are large chylomicrons. These particles are too large to penetrate the intima of the arterial wall and so are not usually associated with an increased risk of $\mathrm{CV}$ disease. However, these patients are at risk of acute pancreatitis. In contrast, in patients with elevated TG levels $<1000 \mathrm{mg} / \mathrm{dL}$, the predominant particle in the circulation is VLDL. Incomplete lipolysis of VLDL leads to the formation of remnant particles, which are small enough to penetrate the intima, leading to injury, inflammation, and atherosclerosis. These TG-rich remnant particles, in addition to carrying TG, carry a large amount of cholesterol. Unlike cholesterol, most cells easily degrade TG, and it is the cholesterol in these particles that is the likely cause of atherosclerosis. Because these particles carry more cholesterol than LDL particles, they are particularly atherogenic. Once trapped within the intimal surface, TG-rich remnants can be taken up directly by macrophages, leading to the formation of foam cells (Fig. 1) [36]. In addition to the direct effects that TG-rich remnants have on the arterial intima, there may be other indirect mechanisms by which these remnant particles cause atherosclerosis [37].

\section{Treating hypertriglyceridemia}

The AHA, National Lipid Association (NLA), Endocrine Society (ES), and the ESC (European Society of Cardiology) and EAS (European Atherosclerosis Society) have all developed guidelines for the classification and treatment of hypertriglyceridemia (Table 1) [5, 6, 11-14]. Although the most recent ACC/AHA cholesterol guidelines do not provide specific recommendations for the treatment of hypertriglyceridemia, they do recommend following the earlier published AHA scientific statement on the treatment of hypertriglyceridemia [7]. The AHA [11] has defined an optimal fasting TG level as $<100 \mathrm{mg} / \mathrm{dL}$. For individuals with fasting TG levels of $<150 \mathrm{mg} / \mathrm{dL}$ or a nonfasting level of $\leq 200 \mathrm{mg} / \mathrm{dL}$, no further testing for hypertriglyceridemia is indicated, although lifestyle changes may be of value based on an individuals $\mathrm{CV}$ risk. If a nonfasting TG level is $\geq 200 \mathrm{mg} / \mathrm{dL}$, then a fasting lipid panel is recommended. The cornerstone for the treatment of hypertriglyceridemia is lifestyle intervention with diet and exercise. However, pharmacologic therapy to lower TG may be considered based on an individuals $\mathrm{CV}$ risk and how high the level of TG are.

\section{Treating very high TG levels ( $\geq 500 \mathrm{mg} / \mathrm{dL})$}

The AHA [11] and NLA [5] define very high TG as $\geq 500 \mathrm{mg} / \mathrm{dL}$, whereas the ES [12] uses a different nomenclature and defines severe hypertriglyceridemia as TG levels of $1000-1999 \mathrm{mg} / \mathrm{dL}$ and very severe hypertriglyceridemia as $\geq 2000 \mathrm{mg} / \mathrm{dL}$. The EAS [13] defines mild to moderate hypertriglyceridemia as $>150$ and $<880 \mathrm{mg} / \mathrm{dL}$ $(10 \mathrm{nmol} / \mathrm{L})$. Severe hypertriglyceridemia is 


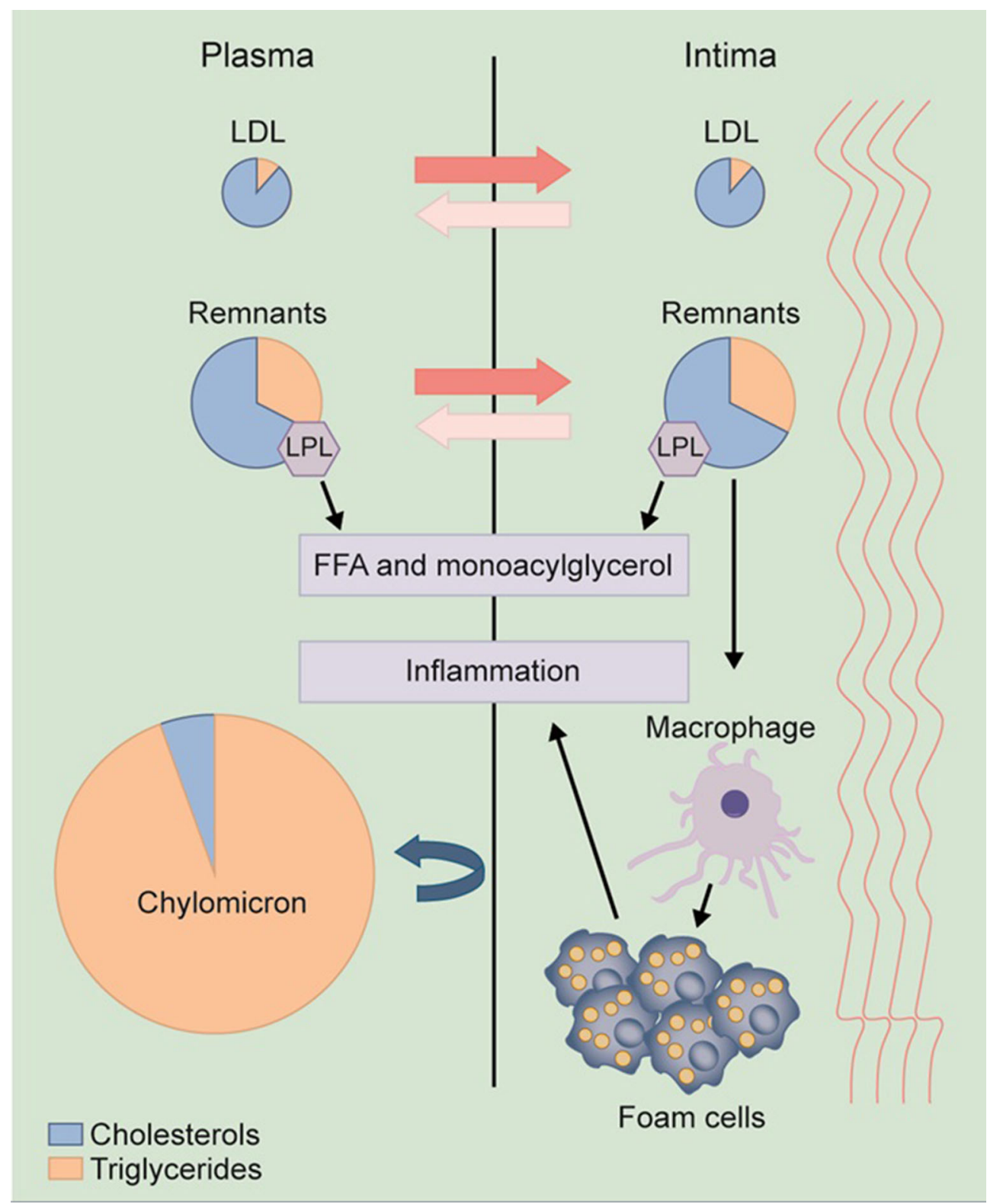

Fig. 1 Mechanisms by which TG and remnant cholesterol may lead to atherosclerosis [35]. TG-rich remnant lipoproteins, similar to LDL cholesterol, are small enough to enter the arterial intima where they can be directly taken up by macrophages, leading to local injury,

defined as $\geq 880 \mathrm{mg} / \mathrm{dL}$. In an individual with very high TG levels, the system to remove VLDL from the circulation is saturated, such that much more severe hypertriglyceridemia can develop with dietary indiscretion or when inflammation, and atherosclerosis. Chylomicrons are too large to enter the arterial intima and hence do not usually lead to atherosclerosis. FFA free fatty acid, $L D L$ low-density lipoprotein, $L P L$ lipoprotein lipase

other metabolic disorders develop in individuals with very high TG levels [41]. For this reason, both the AHA [11] and NLA [5] have chosen a lower threshold than the ES [12] or the ESC and EAS $[13,14]$ at which to target TG to 


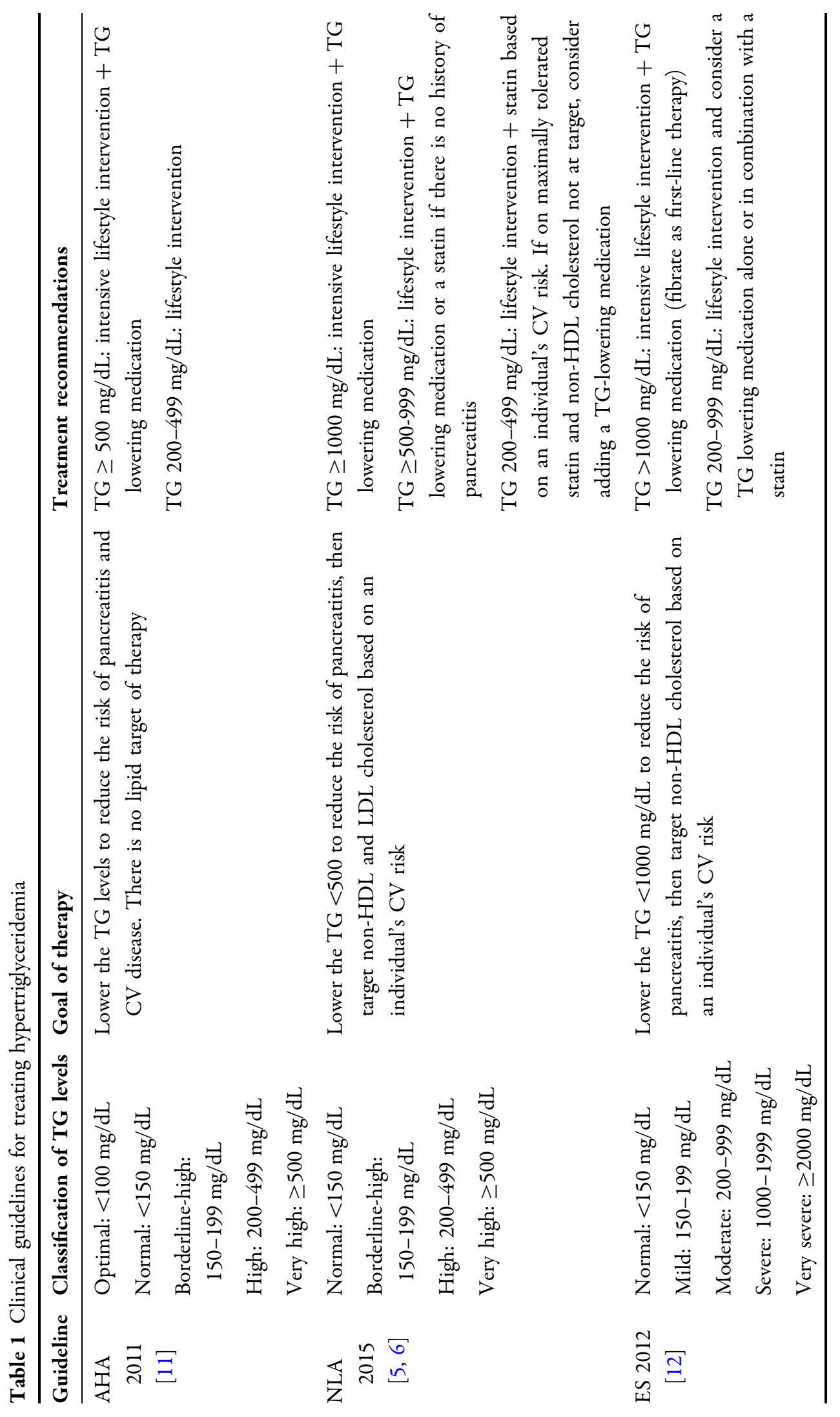




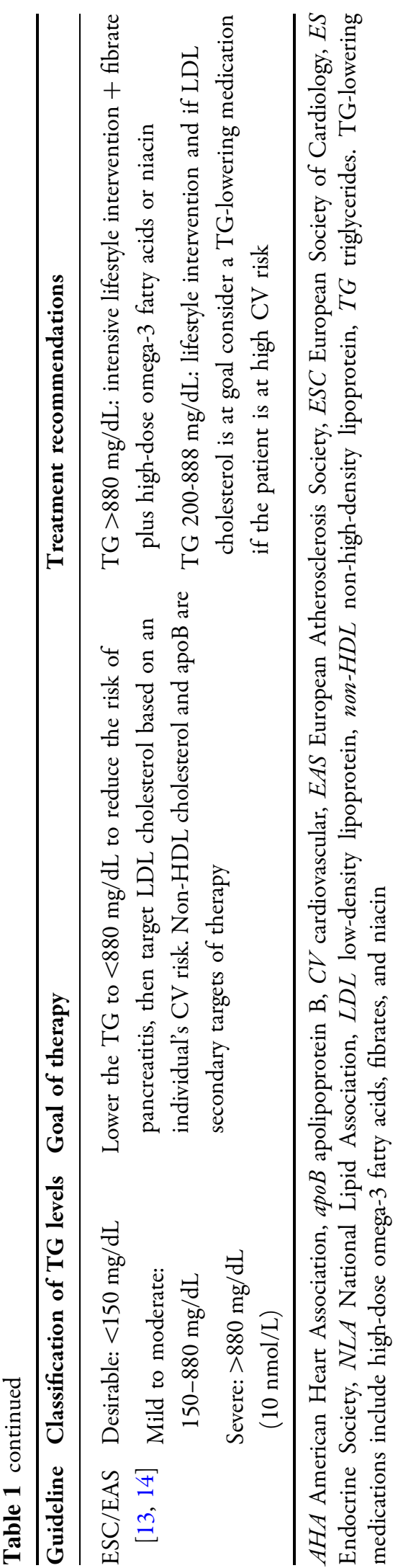

prevent pancreatitis. Although there are some differences among the guidelines as to what defines very high or severe hypertriglyceridemia, there is consensus that the main goal of treating very high TG levels is to reduce the risk of pancreatitis. In individuals with very high TG levels, an evaluation should be undertaken as to the cause of the very high TG levels and intense lifestyle interventions should be undertaken with strict recommendations to limit dietary fat and abstain from alcohol. The NLA in its Part 2 Recommendations for Patient Centered Management of Dyslipidemia recommend limiting fat to $10-15 \%$ of calories, $30-60 \mathrm{~min}$ of exercise most days, and avoidance of alcohol, added sugar, and refined carbohydrates [6]. Once the TGs fall to $<500 \mathrm{mg} / \mathrm{dL}$, dietary fat can be gradually advanced as tolerated. In addition to lifestyle intervention, both the AHA [11] and the NLA [5, 6] recommend TG-lowering medications when the TG levels are $\geq 500 \mathrm{mg} / \mathrm{dL}$. The NLA recommends that when TG levels are $\geq 1000 \mathrm{mg} / \mathrm{dL}$ an agent that primarily lowers TG such as prescription omega-3 fatty acids and fibrates be used as first-line therapy; however, in patients with TG levels of 500-999 mg/dL, if there is no history of pancreatitis a statin may also be considered as first-line therapy. This is because statins have a modest effect on lowering TG. Ezetimibe has only a limited TG-lowering effect, lowering TG by about $5-10 \%$, whereas bile acid sequestrants can increase TG levels $[5,10]$ and should not be used in patients with severe hypertriglyceridemia. Often in patients with very high TG levels, combination TG-lowering therapy is required. The ES [12] recommends drug therapy along with lifestyle intervention to reduce the risk of pancreatitis when the TG levels are $>1000 \mathrm{mg} / \mathrm{dL}$ and recommends that a fibrate be used as first-line therapy for 
individuals with severe hypertriglyceridemia. The recent ESC and EAS guidelines [14] recommend, along with dietary intervention, pharmacological therapy to prevent pancreatitis when the TG levels are severely elevated $(\geq 880 \mathrm{mg} / \mathrm{dL})$. Similar to the ES recommendations [12], a fibrate is the drug of first choice; however, the ESC and EAS also recommend that in patients with severe hypertriglyceridemia, high-dose omega- 3 fatty acids or niacin be initiated along with fibrate therapy [14].

The goal of therapy is to lower the TG to levels at which the risk of pancreatitis is low. The AHA and the ESC and EAS do not recommend a specific target for TG reduction, while the ES recommends a treatment goal for TG levels of $<1000 \mathrm{mg} / \mathrm{dL}$ and the NLA a treatment goal of $<500 \mathrm{mg} / \mathrm{dL}$. However, there may be additional clinical benefit in lowering TG closer to the normal range. In a large retrospective cohort study of 41,210 adults with very high TG levels $(\geq 500 \mathrm{mg} / \mathrm{dL}$ ), the larger the TG reduction, the greater the clinical benefit. In an average follow-up of approximately 90 days, $79 \%$ of patients experienced a reduction in their TG levels to $<500 \mathrm{mg} / \mathrm{dL}$ and $25 \%$ achieved TG levels $<200 \mathrm{mg} / \mathrm{dL}$. The use of TG-lowering therapy was significantly greater in those patients who achieved TG levels $<200 \mathrm{mg} / \mathrm{dL}$ compared to those with higher TG levels in follow-up. Those patients who had a follow-up TG level of $<200 \mathrm{mg} / \mathrm{dL}$ demonstrated the greatest reduction in the risk of pancreatitis [44]. This study suggests that in patients with very high TG levels the greatest clinical benefit occurs when the TG levels are lowered to an almost normal level. However, it should be noted that no randomized prospective clinical trial to date has evaluated the benefit of treating very high TG levels with TG-lowering therapy to reduce the risk of pancreatitis nor identified the optimal level of TG reduction associated with a low risk of pancreatitis.

Patients with very high TG levels may be at increased CV risk even though their TG levels are lowered to a level at which they are no longer at risk for pancreatitis. The decision for additional lipid-lowering therapy should be based on current guidelines and an individual's CV risk. The 2013 ACC/AHA cholesterol guidelines identified four patient groups who would benefit from moderate to high dose statin therapy [7]. If an individual with very high TG falls into one of these patient groups, once the TG are lowered consideration should be given to adding a statin to their TG-lowering therapy. Although most TG-lowering drugs are well tolerated in combination with a statin, it should be noted that gemfibrozil is contraindicated in combination with statins because of the increased risk of serious myopathy $[5,11]$. If the TG levels fall to a normal or borderline level with lifestyle changes and combination lipid-lowering therapy, consideration may be given to discontinuing the non-statin TG-lowering medication. However, the TG levels will need to be monitored closely for any rise in the TG levels. Although the ACC/ AHA guidelines no longer recommend target lipid goals, both the NLA [5], the ES [12], and the ESC and EAS [14] advocate for the use of target lipid goals in clinical practice. Based on an individual's CV risk the NLA recommends both non-HDL and LDL cholesterol be the primary targets of therapy, while the ESC and EAS recommend LDL cholesterol as the primary target of therapy and non-HDL cholesterol and apoliprotein B levels as secondary targets. The ES recommends for individuals with severe hypertriglyceridemia the treatment goal be non-HDL cholesterol. Non-HDL cholesterol is 
total cholesterol minus HDL cholesterol and takes into account not only the cholesterol carried by LDL, but also IDL, VLDL, and VLDL remnants. Epidemiologic studies have shown that non-HDL cholesterol is a better predictor of CV risk than is LDL cholesterol [45], especially when the on-treatment values are discordant [46].

\section{Treating high TG levels (200-499 mg/dL)}

Unlike very high TG levels, individuals with high TG levels (200-499 mg/dL) are not at risk for pancreatitis but may be at risk for $\mathrm{CV}$ disease. All of the guidelines recommend lifestyle changes as first-line therapy for individuals with high TG levels including diet, weight loss, reduced alcohol consumption, and increased physical activity $[5,6,11-14]$. In contrast to the strict restriction of dietary fat for individuals with very high TG levels, individuals with high TG levels should be recommended a diet low in sugar and refined carbohydrates. Even small changes to a patient's diet can have clinically significant effects on TG levels. Eliminating trans fatty acids, such as those found in margarine and bakery products, restricting sugar, refined carbohydrates, and alcohol, and increasing unsaturated fats and marine-based omega-3 products have the potential to reduce TG levels by around 10-20\% $[5,6,11]$. Weight loss can also have a beneficial effect on all lipids and lipoproteins. A 20\% decrease in TG can be achieved with a $5-10 \%$ reduction in body weight $[5,6,11]$. An increase in physical activity can aid weight loss and reduce TG, especially in those who exercise at least moderately [11]. It is important to note that reductions in TG through changes in diet and lifestyle are additive, so it is possible for individuals to achieve significant reductions in TG if all recommendations are implemented [10].
Although the epidemiologic evidence is strong that high TG levels are independently associated with $\mathrm{CV}$ risk, there are no completed outcome studies that specifically targeted individuals with high levels of TG. For this reason, other than lifestyle changes there are no formal guidelines to treat individuals with TG levels of $200-499 \mathrm{mg} / \mathrm{dL}$ with lipid-lowering therapy. However, based on current guidelines many patients with high levels of TG will fall into a $\mathrm{CV}$ risk category that would warrant consideration for statin therapy. Although no statin trial has specifically looked at patients with high TG, secondary analyses from several of the major statin trials have shown a consistent benefit in subsets of patients with high TG alone or in combination with low HDL cholesterol. For example, in the Scandinavian Simvastatin Survival Study (4S), simvastatin reduced major $\mathrm{CV}$ events by $45 \%$ compared with placebo. Furthermore, CV events were reduced more in patients with high TG and low HDL-C levels than in patients with isolated elevations in LDL cholesterol [47]. Secondary analyses from trials of other lipid-lowering drugs have shown similar results. In both the Helsinki Heart Study (HHS) [48] and the Veterans Affairs HDL Intervention Trial (VA-HIT) [49], gemfibrozil significantly reduced the incidence of $\mathrm{CV}$ events compared with placebo in the overall study population. In both studies, the subgroups of patients with elevated TG levels showed greater CV risk reduction than the general study population $[50,51]$. In contrast to these studies, there was no improvement in $\mathrm{CV}$ outcomes in two large $\mathrm{CV}$ disease prevention studies in patients with diabetes: the Fenofibrate Intervention and Event Lowering in Diabetes (FIELD) trial, [52] which compared fenofibrate with placebo, and the Action to Control Cardiovascular Risk in Diabetes (ACCORD) trial [53], which compared 
fenofibrate plus simvastatin with simvastatin alone. However, in patients with baseline TG $>204 \mathrm{mg} / \mathrm{dL}$ and low HDL cholesterol, a 27\% risk reduction $(p=0.005)$ was seen in FIELD [54], and a 31\% reduction in CV events $(p=0.057)$ was seen in ACCORD [53]. As with the fenofibrate studies, in the Atherothrombosis Intervention in Metabolic syndrome with low HDL/high triglycerides: Impact on Global Health outcomes (AIM-HIGH) study, extended-release niacin in combination with a statin failed to reduce $\mathrm{CV}$ events in high-risk men and women [55]. In the Heart Protection Study 2-Treatment of HDL to Reduce the Incidence of Vascular Events (HPS2-THRIVE) trial extended-release niacin and laropiprant when added to a statin did not significantly reduce major $\mathrm{CV}$ events in patients with atherosclerotic vascular disease, but increased the risk of bleeding, infection, worsening diabetic control, and other adverse events associated with the gastrointestinal and musculoskeletal systems [56]. However, in the subgroup of patients in AIM-HIGH with baseline TG $>200 \mathrm{mg} / \mathrm{dL}$ and HDL cholesterol $<32 \mathrm{mg} / \mathrm{dL}$, a significant reduction in CV events was demonstrated [57]. With regard to omega-3 fatty acids, the Japanese Eicosapentaenoic Acid (EPA) Lipid Intervention Study (JELIS) demonstrated a $19 \%$ reduction in major CV events in the EPA group compared with the statin-alone group [58]; however, in patients with elevated TG and low HDL cholesterol at baseline an even greater CV risk reduction was seen. EPA treatment lowered the risk of a major cardiac event by $53 \%$ in those patients with elevated TG and low HDL cholesterol compared to the statin-alone group [59]. Taken together, the evidence from these subanalyses in patients with elevated TG suggests that lowering TG may lead to favorable CV outcomes.
Two large-scale outcomes studies are currently investigating the effect of prescription omega-3 fatty acids in combination with statins on $\mathrm{CV}$ events in high-risk patients with high TG levels. The Reduction of Cardiovascular Events with EPA-Intervention Trial (REDUCE-IT; NCT01492361) is assessing the effect of icosapent ethyl (IPE) $\left(\right.$ Vascepa $\left.^{\circledR}\right)$ in statin-treated patients with or at high risk for CV disease who have high TG levels $(\geq 200 \mathrm{mg} / \mathrm{dL}$ ). The endpoint is a composite of CV death, myocardial infarction, stroke, coronary revascularization, and hospitalization for unstable angina and is expected to complete in December 2017 [60]. The STatin Residual risk reduction with EpaNova in hiGh cardiovascular risk paTients with Hypertriglyceridemia (STRENGTH; NCT02104817) study is evaluating the effect of omega-3 carboxylic acids (OM3CA) $\left(\right.$ Epanova $^{\circledR}$ ) in statin-treated patients at high risk for CV disease with TG levels $\geq 180 \mathrm{mg}$ / $\mathrm{dL}$. The endpoint is the first occurrence of a major adverse coronary event, including $\mathrm{CV}$ death, nonfatal myocardial infarction, nonfatal stroke, coronary revascularization, or hospitalization for unstable angina and is expected to complete in June 2019 [61].

As we await the results of these trials, individuals with high TG levels between 200 and $499 \mathrm{mg} / \mathrm{dL}$ should be treated with lifestyle intervention and should be considered for statin therapy based on current cholesterol guidelines and their $\mathrm{CV}$ risk. The NLA recommends that for patients whose TG levels remain high despite statin therapy, the clinician should consider a TG-lowering drug such as a fibrate or high-dose omega-3 fatty acids based on their CV risk and their non-HDL cholesterol goal $[5,6]$. 
Treating borderline high TG levels (150-199 mg/dL)

For individuals with borderline high TG levels, pharmacotherapy is not recommended to lower TG but rather therapeutic lifestyle changes remain the focus of treatment to help lower TG levels $[5,11]$. As with patients with high TG levels a diet low in sugar and refined carbohydrates, weight loss, and exercise will likely bring the TG levels to the normal or optimal range.

\section{The use of omega-3 fatty acid preparations to lower TG levels}

Omega-3 fatty acids are available in the form of prescription drugs or non-prescription dietary supplements and lower fasting and postprandial TG levels in a dose-dependent manner [11]. Prescription omega-3 fatty acids are more potent and more effective than non-prescription supplements and are the preferred choice for lowering very high TG [62]. The prescription omega-3 fatty acids that are currently approved in the US to treat patients with very high TG levels $(\geq 500 \mathrm{mg} /$ $\mathrm{dL}$ ) are primarily available as EPA alone or in combination with docosahexaenoic acid (DHA) [63-66].

The mechanism by which omega-3 fatty acids lower TG is multifactorial and is thought to involve decreased hepatic lipogenesis, increased $\beta$-oxidation of fatty acids, inhibition of key enzymes involved in hepatic TG synthesis, and increased expression of lipoprotein lipase [67-72]. Together with their TG-lowering effects, omega-3 fatty acids are also thought to have anti-arrhythmic [73], anti-thrombotic, anti-atherosclerotic [74], and anti-inflammatory effects [75], as well as promoting improvements in endothelial function [76] and lowering blood pressure [77]. All of these effects may contribute to the $\mathrm{CV}$ benefits associated with omega-3 fatty acids.

There are currently three prescription omega-3 fatty acid formulations approved in the US for the management of hypertriglyceridemia: (1) a mixture of long chain omega-3 fatty acid ethyl esters (OM3EE), primarily EPA, and DHA (Lovaza ${ }^{\circledR}$, Omtryg $^{\mathrm{TM}}$, and some generics). Each 1-g capsule of OM3EE contains $465 \mathrm{mg}$ of EPA and $375 \mathrm{mg}$ of DHA; $[64,65]$, (2) IPE (EPA ethyl esters) $\left(\right.$ Vascepa $\left.^{\circledR}\right)$, with each 1 -g capsule containing $1 \mathrm{~g}$ of IPE; [63], and (3) OM3CA, a mixture of long-chain omega-3 fatty acids in free fatty acid form, primarily EPA, DHA, and docosapentaenoic acid (Epanova ${ }^{\circledR}$ ). Each 1-g capsule contains 75\% EPA plus DHA [66]. DHA and EPA, the main components of omega-3 fatty acids, have different effects on LDL cholesterol, HDL cholesterol, and TG. A 2011 meta-analysis of studies directly comparing the effects of the DHA and EPA components found that there was a greater reduction in TG, at the expense of a greater increase in LDL cholesterol with DHA compared with EPA. In addition, DHA increased HDL cholesterol but EPA did not when compared with placebo [78]. Omega-3 fatty acids also reduce apolipoprotein C3, a key contributor to the development of hypertriglyceridemia and the progression of atherosclerosis and CV disease [79].

\section{Effects of omega-3 fatty acids on TG, LDL cholesterol, and other lipoproteins}

Table 2 summarizes data from clinical studies investigating the effect of each of the three prescription omega-3 fatty acid formulations on TG, LDL cholesterol, and HDL cholesterol in patients with hypertriglyceridemia. However, it should be noted that there is a lack of 


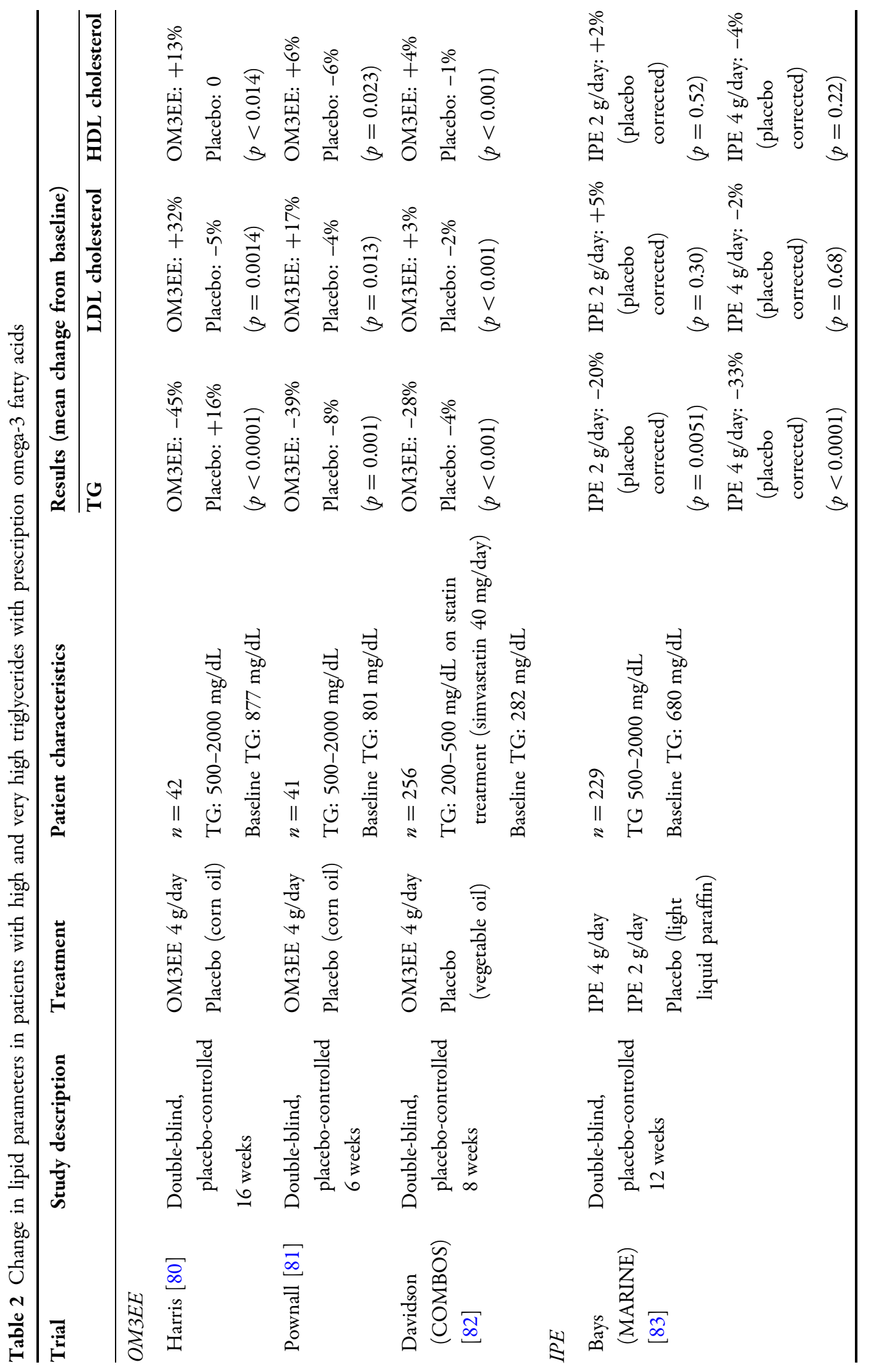




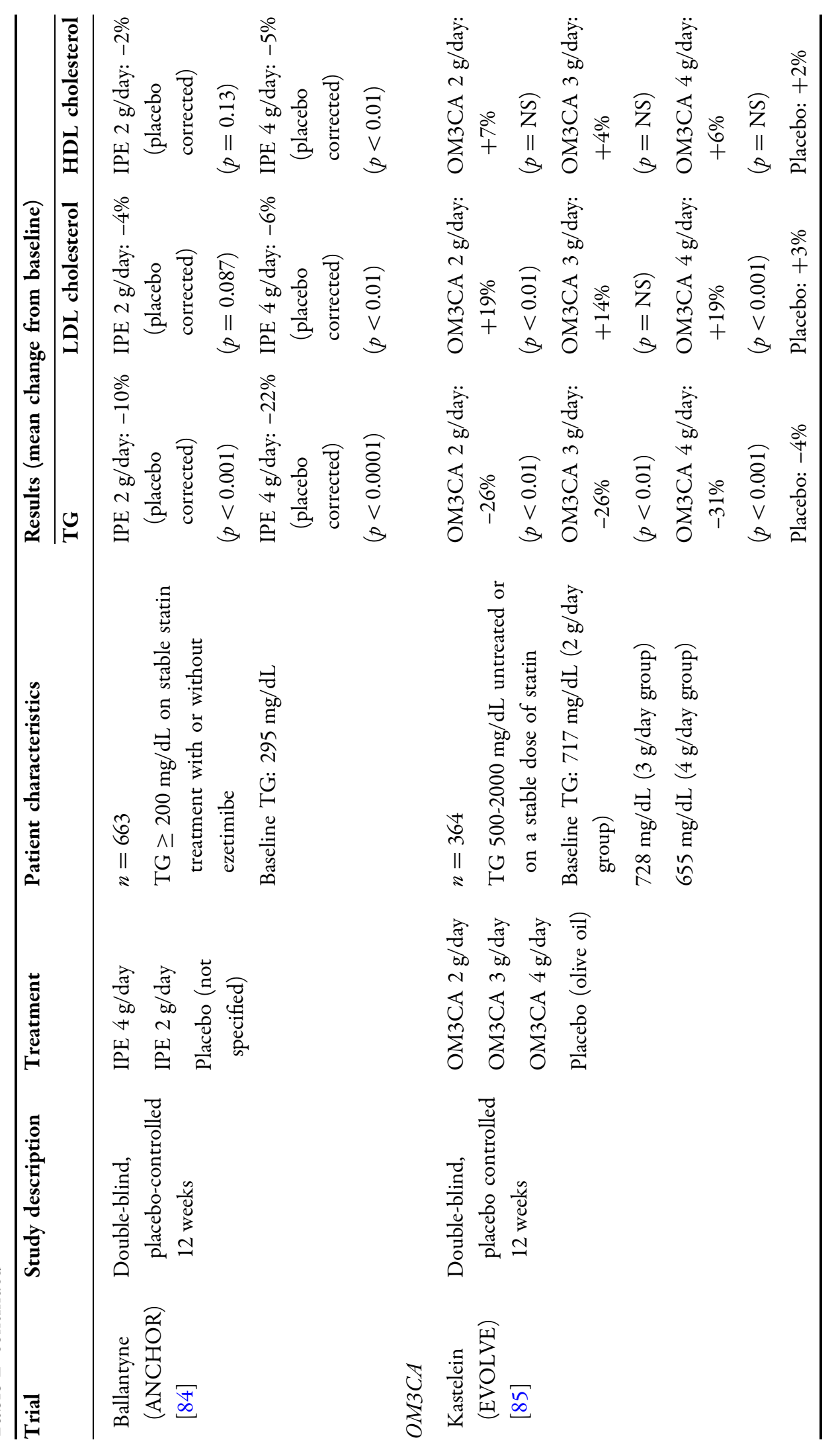




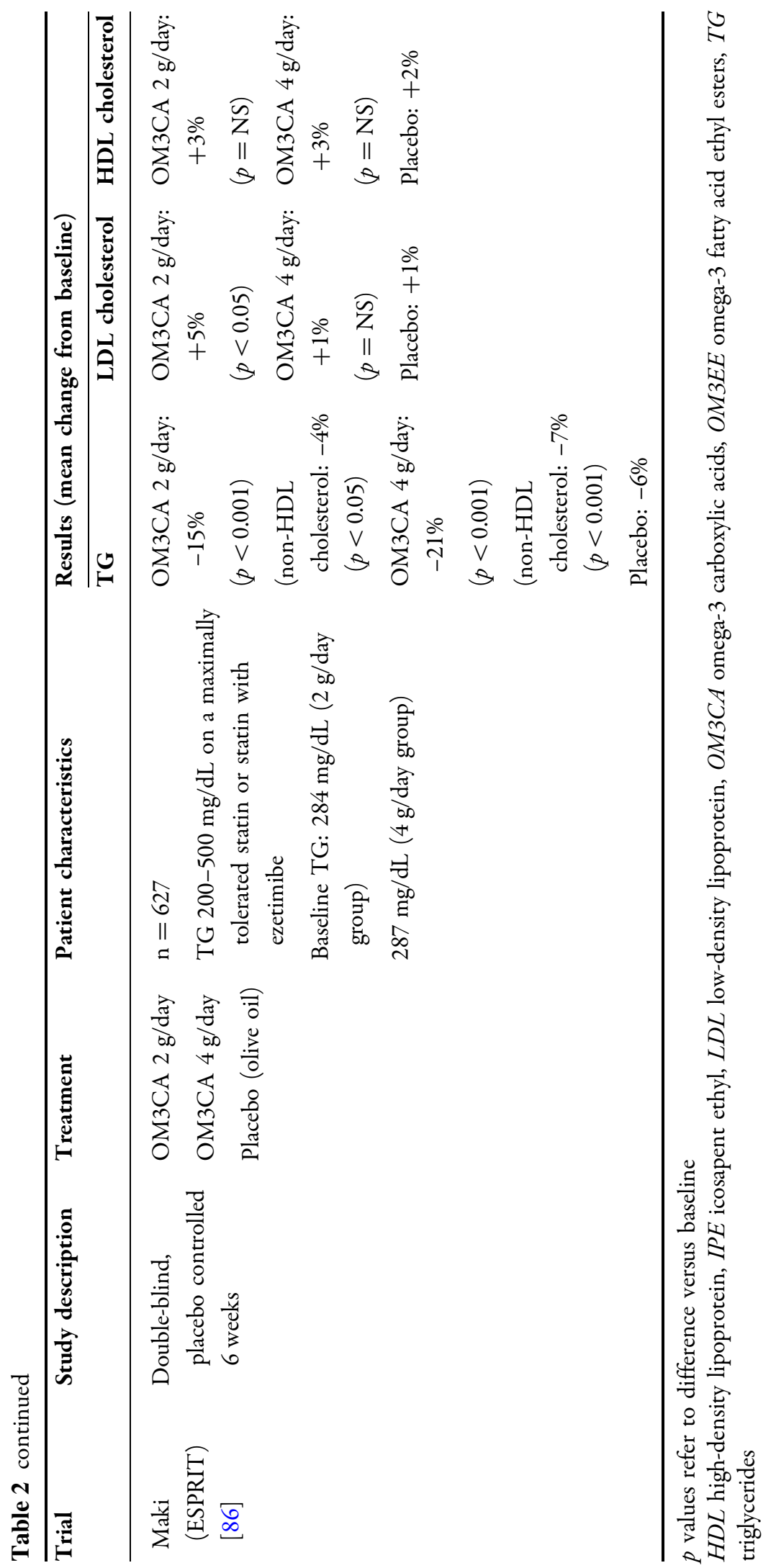


consistency between placebo groups in these studies; consequently, the results should not be directly compared.

Several double-blind, placebo-controlled studies have investigated the efficacy of OM3EE $4 \mathrm{~g} /$ day in patients with severe hypertriglyceridemia [80-82]. In the two small studies of patients with very high TG levels between 500 and $2000 \mathrm{mg} / \mathrm{dL}$ (1 with 42 patients and the other with 41 patients) the mean baseline TG levels were 877 and $801 \mathrm{mg} /$ $\mathrm{dL}$, respectively [80, 81]. In the third larger study, 256 patients with lower levels of TG were enrolled. In these patients with high TG levels between 200 and $500 \mathrm{mg} / \mathrm{dL}$, the mean baseline TG level was $282 \mathrm{mg} / \mathrm{dL}$ [82]. In all three studies, OM3EE significantly reduced TG levels compared with baseline $(p \leq 0.001)$, with reductions that ranged from $28 \%$ to $45 \%$. The higher the baseline TG level, the greater the reduction in TG levels seen [80]. OM3EE also produced significant increases in HDL cholesterol over the course of the studies, ranging from a $4 \%$ to $13 \%$ increase $(p \leq 0.023)$. OM3EE treatment was also associated with significant increases in LDL-C cholesterol from $3 \%$ to $32 \%$ ( $p \leq 0.013$ ), which correlated with the decrease in TG levels. However, the increase in LDL cholesterol was attenuated when OM3EEs were given along with statin therapy.

The efficacy of IPE 2 and $4 \mathrm{~g}$ /day has been investigated in two double-blind, placebo-controlled, 12-week studies. As with the OM3EE studies, the mean baseline TG level differed between the two studies [83, 84]. In the Multi-center, placebo-controlled, Randomized, double-bliNd, 12-week study with an open-label Extension (MARINE) study, 229 patients with very high TG levels, between 500 and $2000 \mathrm{mg} / \mathrm{dL}$, were randomized to IPE $2 \mathrm{~g} /$ day, IPE $4 \mathrm{~g} /$ day, or placebo. The baseline
TG levels were $657 \mathrm{mg} / \mathrm{dL}$ in the IPE $2 \mathrm{~g} /$ day group and $680 \mathrm{mg} / \mathrm{dL}$ in the IPE $4 \mathrm{~g}$ /day group [83]. At 12 weeks, there were significant placebo-corrected reductions in TG of $20 \%$ with IPE $2 \mathrm{~g} /$ day and $33 \%$ with $4 \mathrm{~g}$ /day $(p \leq 0.005)$. IPE $4 \mathrm{~g} /$ day also produced a non-significant placebo-corrected reduction in LDL cholesterol and HDL cholesterol of 2 and $4 \%$, respectively. IPE $2 \mathrm{~g} /$ day produced non-significant placebo-corrected increases in LDL cholesterol and HDL cholesterol of 5 and $2 \%$, respectively. In the ANCHOR study the effects of IPE 2 and $4 \mathrm{~g}$ /day were evaluated in patients with high TG levels $\geq 200$ and $<500 \mathrm{mg} / \mathrm{dL}$. In this study of 663 patients the mean baseline TG levels were $254 \mathrm{mg} / \mathrm{dL}$ in the IPE $2 \mathrm{~g} /$ day group and $265 \mathrm{mg} / \mathrm{dL}$ in the IPE $4 \mathrm{~g}$ /day group [84]. IPE $2 \mathrm{~g}$ /day and $4 \mathrm{~g}$ /day significantly reduced placebo-corrected TG levels by $10 \%$ and $22 \%$, respectively $(p<0.001)$. IPE $4 \mathrm{~g} /$ day also produced significant $\quad(p<0.01) \quad$ placebo-corrected reductions in LDL cholesterol and HDL cholesterol of $6 \%$ and $5 \%$, respectively. IPE $2 \mathrm{~g} /$ day produced placebo-corrected reductions in LDL cholesterol of $4 \%$ and HDL cholesterol of 2\%; however, these changes were not statistically significant.

Three doses of OM3CA (2, 3, and $4 \mathrm{~g}$ /day) have been investigated across two double-blind, parallel-group studies. The EpanoVa fOr Lowering Very high triglyceridEs (EVOLVE) study randomized 364 patients with baseline mean TG levels of 655-728 mg/dL to OM3CA 2, 3 , or $4 \mathrm{~g} /$ day [85]. At 12 weeks, OM3CA 2-4 g/day significantly reduced TG levels by 26 , 26, and $31 \%$, respectively $(p<0.01)$. OM3CA also produced increases in HDL cholesterol of 7, 4, and 6\%, respectively, though this did not reach statistical significance. LDL cholesterol increased by $19 \%$ $(p<0.01)$ at the $2 \mathrm{~g} /$ day dose, by $14 \%(p=\mathrm{NS})$ 


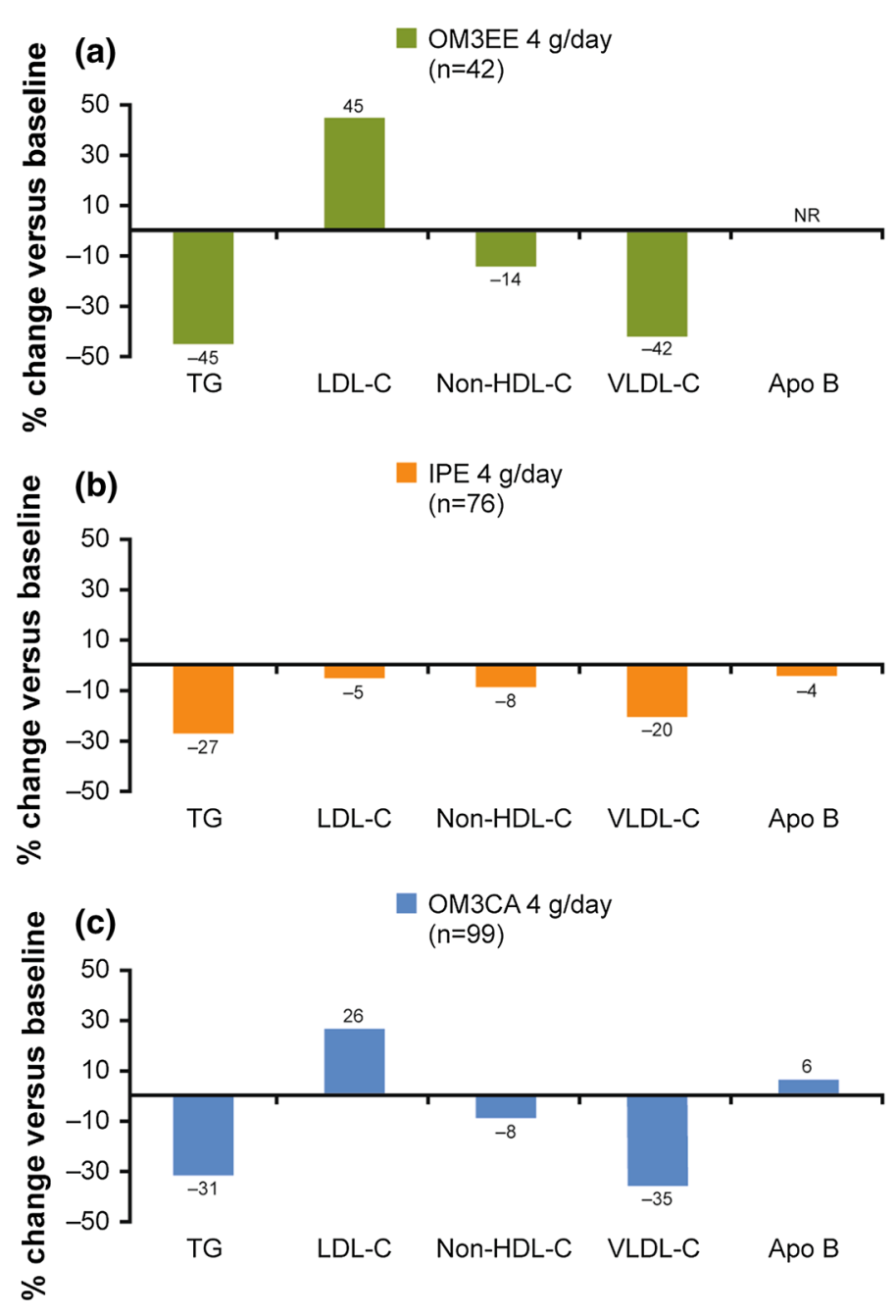

Fig. 2 Change in lipid parameters in patients with high and very high triglycerides with prescription omega-3 fatty acid preparations. a OM3EE [64, 65]; b IPE [63]; c OM3CA [66]; Apo B apolipoprotein B, IPE icosapent ethyl, non- $H D L-C$ non-high-density lipoprotein cholesterol, $L D L-C$ low-density lipoprotein cholesterol, $O M 3 C A$ omega-3 carboxylic acids, $N R$ not reported, $O M 3 E E$

at the $3 \mathrm{~g} /$ day dose, and by $19 \%(p<0.001)$ at the $4 \mathrm{~g} /$ day dose. In the Epanova combined with a Statin in Patients with hypertriglyceridemIa to Reduce non-HDL cholesTerol (ESPRIT) study, 627 patients with baseline mean TG levels of $280-287 \mathrm{mg} / \mathrm{dL}$ had reductions in TG of $15 \%$ with OM3CA 2 g/day and $21 \%$ with OM3CA $4 \mathrm{~g} /$ day $(p<0.001)$ [86]. The primary endpoint in this trial was change in omega-3 fatty acid ethyl esters, $T G$ triglycerides, $V L D L-C$ very low-density lipoprotein cholesterol. Information not provided for the effect of OM3EE on apo B. Results are from different studies, as reported in the respective prescribing information, and cannot be directly compared

non-HDL cholesterol, which was reduced by $4 \%$ $(p<0.05)$ and $7 \%(p<0.001)$ with OM3CA $2 \mathrm{~g} /$ day and OM3CA $4 \mathrm{~g}$ /day, respectively. HDL cholesterol increased by $3 \%$ in both groups, and LDL cholesterol increased by 5 and $1 \%$ with OM3CA $2 \mathrm{~g}$ /day and OM3CA $4 \mathrm{~g} /$ day, respectively.

Figure 2 shows the lipid-lowering effects of each of these three formulations at their highest 
dose available for prescription on TG levels and various other lipoproteins in patients with TG $\geq 500 \mathrm{mg} / \mathrm{dL}$, as detailed in their respective prescribing information [63-66]. OM3CA and OM3EE have both been shown to have beneficial effects on non-HDL cholesterol and VLDL cholesterol. OM3CAs are also associated with a small (6\%) increase in apolipoprotein B. IPE $4 \mathrm{~g}$ /day also has positive effects on non-HDL cholesterol, total cholesterol, VLDL cholesterol, and apolipoprotein B. However, the reductions in VLDL cholesterol are not as large with IPE as they are with OM3CA and OM3EE (20 vs. 35 and $42 \%$, respectively). Although there have been no comparison studies between the available prescription omega-3 fatty acid preparations with regard to their lipid-lowering effects, in general those formulations high in DHA appear to provide greater TG-lowering effects, while those higher in EPA provide a modest lowering of LDL cholesterol [78].

There are some differences in bioavailability between the three prescription omega-3 fatty acid formulations. IPE and OM3EE both have to be hydrolyzed by pancreatic lipase before they can be absorbed [87]. As levels of pancreatic lipase directly correlate with the type and amount of lipids consumed, the absorption of IPE and OM3EE is highly dependent on the fat content of meals [88]. Given that patients with hypertriglyceridemia are advised to adhere to low-fat diets, the absorption of these two formulations may be adversely affected. Studies have shown that with low-fat diets, the bioavailability of EPA and DHA with OM3CA was four times higher than with OM3EE [89]. A small pharmacokinetic study of an investigational omega-3 fatty acid medication containing predominately EPA and docosapentaenoic acid (DPA) dosed with low-fat meals exhibited significantly greater bioavailability when compared to IPE in patients with hypertriglyceridemia [90]. Those formulations such as those containing OM3CA that do not require pancreatic lipase for absorption can be taken at any time of the day and are not restricted to meal times, providing more flexibility around dosing [89]. The greater bioavailability afforded by OM3CA formulations of omega-3 fatty acids may provide greater reductions in $\mathrm{TG}$ at lower doses compared to other omega-3 fatty acid formulations. However, to date no head-to-head comparison studies have been performed among the different available omega-3 fatty acid formulations.

Supplements and non-prescription omega-3 fatty acid products are not subject to the same very strict regulations that prescription formulations of omega-3 fatty acids are. As a result, patients may be taking insufficient amounts of EPA and DHA to have a clinically significant effect on TG levels. In a recent study of 32 fish oil supplements by a New Zealand research team, it was found that there was a noticeable difference between the claimed content and the actual content of EPA and DHA. On average, the supplements were found to contain just $68 \%$ of the claimed content [91]. The researchers also found that there were high levels of oxidation in the fish oils, with the majority exceeding the recommended levels of oxidation markers, which may explain the gastrointestinal side effects commonly seen with these over-the-counter supplements.

\section{CONCLUSION}

It is estimated that 77 million adults in the US are at risk of $\mathrm{CV}$ disease and pancreatitis because of elevated TG levels. When TG levels are $>1000 \mathrm{mg} / \mathrm{dL}$, the predominant particles carrying TG are large chylomicrons, which are 
believed to cause hyperviscosity, leading to ischemia and acidosis in pancreatic capillaries, and ultimately pancreatitis. In contrast, when TG levels are $<1000 \mathrm{mg} / \mathrm{dL}$, the predominant particles carrying TG are VLDL, which are small enough to penetrate the intima, leading to injury, inflammation, and atherosclerosis [34]. In individuals with high TG levels between 200 and $499 \mathrm{mg} / \mathrm{dL}$ the primary focus for treatment is lifestyle intervention, with diet and exercise $[5,10]$. Statins may be considered for these patients based on current cholesterol guidelines $[5,6]$. For patients on a statin who have persistently high TG levels despite lifestyle interventions, additional TG-lowering therapy with prescription omega 3 fatty acids, fibrates, or niacin may be considered on an individual basis. When TG levels are $\geq 500 \mathrm{mg} / \mathrm{dL}$, and especially when they are $\geq 1000 \mathrm{mg} / \mathrm{dL}$, the primary treatment strategy is to reduce TG levels with a TG-lowering drug to reduce the risk of pancreatitis [5, 10, 12, 13]. High-dose prescription omega-3 fatty acids have been shown to reduce TG levels by up to $50 \%$ [10]. The three prescription omega- 3 fatty acid formulations currently approved in the US differ in their content of EPA and DHA. Those formulations high in DHA provide greater TG-lowering effects, while those higher in EPA provided a modest lowering of LDL-C. The results of two ongoing, large-scale outcomes studies are awaited to confirm the effect of prescription omega-3 fatty acids on reducing CV events.

\section{ACKNOWLEDGEMENTS}

No funding or sponsorship was received for this study or publication of this article. Medical writing support was provided by Kerren Davenport, Prime Medica Ltd., Knutsford,
Cheshire, UK, and funded by AstraZeneca. The content of this manuscript is solely the responsibility of the author. The author received no funding for the development of this manuscript. All named authors meet the International Committee of Medical Journal Editors (ICMJE) criteria for authorship for this manuscript, take responsibility for the integrity of the work as a whole, and have given final approval for the version to be published.

Disclosures. Dean G. Karalis has served as a consultant for Sanofi and Regeneron Pharmaceuticals.

Compliance with Ethics Guidelines. This article is based on previously conducted studies and does not involve any new studies of human or animal subjects performed by any of the authors.

Open Access. This article is distributed under the terms of the Creative Commons Attribution-NonCommercial 4.0 International License (http://creativecommons.org/licenses/ by-nc/4.0/), which permits any noncommercial use, distribution, and reproduction in any medium, provided you give appropriate credit to the original author(s) and the source, provide a link to the Creative Commons license, and indicate if changes were made.

\section{REFERENCES}

1. Heron M. Deaths: leading causes for 2012. National Vital Statistics Reports. 2015;64.

2. Murphy SA, Cannon CP, Wiviott SD, McCabe $\mathrm{CH}$, Braunwald E. Reduction in recurrent cardiovascular events with intensive lipid-lowering statin therapy compared with moderate lipid-lowering statin therapy after acute coronary syndromes from the PROVE IT-TIMI 22 (Pravastatin or Atorvastatin Evaluation and Infection Therapy-Thrombolysis In 
Myocardial Infarction 22) trial. J Am Coll Cardiol. 2009;54:2358-62.

3. Tikkanen MJ, Szarek M, Fayyad R, et al. Total cardiovascular disease burden: comparing intensive with moderate statin therapy insights from the IDEAL (incremental decrease in end points through aggressive lipid lowering) trial. J Am Coll Cardiol. 2009;54:2353-7.

4. Baigent C, Blackwell L, Emberson J, et al. Efficacy and safety of more intensive lowering of LDL cholesterol: a meta-analysis of data from 170,000 participants in 26 randomised trials. Lancet. 2010;376:1670-81.

5. Jacobson TA, Ito MK, Maki KC, et al. National Lipid Association recommendations for patient-centered management of dyslipidemia: part 1-full report. J Clin Lipidol. 2015;9:129-69.

6. Jacobson TA, Maki KC, Orringer CE, et al. National Lipid Association recommendations for patient-centered management of dyslipidemia: part 2. J Clin Lipidol. 2015;9:S1-122.

7. Stone NJ, Robinson JG, Lichtenstein AH, et al. 2013 ACC/AHA guideline on the treatment of blood cholesterol to reduce atherosclerotic cardiovascular risk in adults: a report of the American College of Cardiology/American Heart Association Task Force on Practice Guidelines. J Am Coll Cardiol. 2014;63:2889-934.

8. Miller M, Cannon CP, Murphy SA, Qin J, Ray KK, Braunwald E. Impact of triglyceride levels beyond low-density lipoprotein cholesterol after acute coronary syndrome in the PROVE IT-TIMI 22 trial. J Am Coll Cardiol. 2008;51:724-30.

9. Faergeman O, Holme I, Fayyad R, et al. Plasma triglycerides and cardiovascular events in the treating to new targets and incremental decrease in end-points through aggressive lipid lowering trials of statins in patients with coronary artery disease. Am J Cardiol. 2009;104:459-63.

10. Cannon CP, Blazing MA, Giugliano RP, et al. Ezetimibe added to statin therapy after acute coronary syndromes. N Engl J Med. 2015;372:2387-97.

11. Miller M, Stone NJ, Ballantyne C, et al. Triglycerides and cardiovascular disease: a scientific statement from the American Heart Association. Circulation. 2011;123:2292-333.

12. Berglund L, Brunzell JD, Goldberg AC, et al. Evaluation and treatment of hypertriglyceridemia: an Endocrine Society clinical practice guideline. J Clin Endocrinol Metab. 2012;97:2969-89.
13. Catapano AL, Reiner Z, DeBacker G, et al. The Task Force for the management of dyslipidemia of the European Society of Cardiology (ESC) and the European Atherosclerosis Society (EAS). Atherosclerosis. 2011;217:S1-44.

14. Catapano AL, Graham I, DeBacker G, et al. 2016 ESC/EAS guidelines for the management of dyslipidemias. The task force for the management of dyslipidemia of the European Society of Cardiology (ESC) and European Atherosclerosis Society (EAS). Atherosclerosis. 2016;253:281-344.

15. National Lipid Association Triglyceride Awareness Survey results. Available from: https://www.lipid. org/search/node/Hypertriglyceridemia\%20Aware ness\%20Survey\%20Results. Accessed August 11, 1016.

16. Food and Drug Administration. Withdrawal of approval of indications related to the coadministration with statins in applications for niacin extended-release tablets and fenofibric acid delayed-release capsules. Available from: https://s3. amazonaws.com/public-inspection.federalregister. gov/2016-08894.pdf. Accessed April 29, 2016.

17. Cohen JD, Cziraky MJ, Cai Q, et al. 30-year trends in serum lipids among United States adults: results from the national health and nutrition examination surveys II, III, and 1999-2006. Am J Cardiol. 2010;106:969-75.

18. Flegal KM, Kruszon-Moran D, Carroll MD, Fryar CD, Ogden CL. Trends in obesity among adults in the United States, 2005 to 2014. JAMA. 2016;315:2284-91.

19. Christian JB, Bourgeois N, Snipes R, Lowe KA. Prevalence of severe (500 to $2000 \mathrm{mg} / \mathrm{dL})$ hypertriglyceridemia in United States adults. Am J Cardiol. 2011;107:891-7.

20. Carroll M, Kit B, Lacher D. Trends in elevated triglyceride in adults: United States, 2001-2012. NCHS Data Brief. 2015:1-8.

21. Sumner AE, Finley KB, Genovese DJ, Criqui $\mathrm{MH}$, Boston RC. Fasting triglyceride and the triglyceride-HDL cholesterol ratio are not markers of insulin resistance in African Americans. Arch Intern Med. 2005;165:1395-400.

22. Chhabra S, Narang R, Krishnan LR, et al. Apolipoprotein C3 SstI polymorphism and triglyceride levels in Asian Indians. BMC Genet. 2002;3:9.

23. Resnick HE, Foster GL, Bardsley J, Ratner RE. Achievement of American Diabetes Association clinical practice recommendations among U.S. adults with diabetes, 1999-2002: the National 
Health and Nutrition Examination Survey. Diabetes Care. 2006;29:531-7.

24. Weiner DE, Sarnak MJ. Managing dyslipidemia in chronic kidney disease. J Gen Intern Med. 2004;19:1045-52.

25. Tenner S, Baillie J, DeWitt J, Vege SS. American College of Gastroenterology guideline: management of acute pancreatitis. Am J Gastroenterol. 2013;108:1400-15.

26. Scherer J, Singh VP, Pitchumoni CS, Yadav D. Issues in hypertriglyceridemic pancreatitis: an update. J Clin Gastroenterol. 2014;48:195-203.

27. Murphy MJ, Sheng X, MacDonald TM, Wei L. Hypertriglyceridemia and acute pancreatitis. JAMA Intern Med. 2013;173:162-4.

28. Linares CL, Pelletier AL, Czernichow S, et al. Acute pancreatitis in a cohort of 129 patients referred for severe hypertriglyceridemia. Pancreas. 2008;37:13-8.

29. Ewald N, Hardt PD, Kloer HU. Severe hypertriglyceridemia and pancreatitis: presentation and management. Curr Opin Lipidol. 2009;20:497-504.

30. Yang F, Wang Y, Sternfeld L, et al. The role of free fatty acids, pancreatic lipase and $\mathrm{Ca}^{+}$signalling in injury of isolated acinar cells and pancreatitis model in lipoprotein lipase-deficient mice. Acta Physiol (Oxf.). 2009;195:13-28.

31. Yadav D, Pitchumoni CS. Issues in hyperlipidemic pancreatitis. J Clin Gastroenterol. 2003;36:54-62.

32. Nordestgaard BG, Benn $M$, Schnohr $P$, Tybjaerg-Hansen A. Nonfasting triglycerides and risk of myocardial infarction, ischemic heart disease, and death in men and women. JAMA. 2007;298:299-308.

33. Freiberg JJ, Tybjaerg-Hansen A, Jensen JS, Nordestgaard BG. Nonfasting triglycerides and risk of ischemic stroke in the general population. JAMA. 2008;300:2142-52.

34. Di Angelantonio E, Sarwar N, Perry P, et al. Major lipids, apolipoproteins, and risk of vascular disease. JAMA. 2009;302:1993-2000.

35. Sarwar N, Danesh J, Eiriksdottir G, et al. Triglycerides and the risk of coronary heart disease: 10,158 incident cases among 262,525 participants in 29 Western prospective studies. Circulation. 2007;115:450-8.

36. Nordestgaard BG, Varbo A. Triglycerides and cardiovascular disease. Lancet. 2014;384:626-35.
37. Chapman MJ, Ginsberg HN, Amarenco P, et al. Triglyceride-rich lipoproteins and high-density lipoprotein cholesterol in patients at high risk of cardiovascular disease: evidence and guidance for management. Eur Heart J. 2011;32:1345-61.

38. Schwartz GG, Abt M, Bao W, et al. Fasting triglycerides predict recurrent ischemic events in patients with acute coronary syndrome treated with statins. J Am Coll Cardiol. 2015;65:2267-75.

39. Sarwar N, Sandhu MS, Ricketts SL, et al. Triglyceride-mediated pathways and coronary disease: collaborative analysis of 101 studies. Lancet. 2010;375:1634-9.

40. Varbo A, Benn M, Tybjaerg-Hansen A, Jorgensen $A B$, Frikke-Schmidt R, Nordestgaard BG. Remnant cholesterol as a causal risk factor for ischemic heart disease. J Am Coll Cardiol. 2013;61:427-36.

41. The TG, HDL Working Group of the Exome Sequencing Project, National Heart, Lung, and Blood Institute, Crosby J, Peloso GM, et al. Loss-of-function mutations in APOC3, triglycerides, and coronary disease. N Engl J Med. 2014;371:22-31.

42. Jorgensen AB, Frikke-Schmidt R, Nordestgaard BG, Tybjaerg-Hansen A. Loss-of-function mutations in APOC3 and risk of ischemic vascular disease. $\mathrm{N}$ Engl J Med. 2014;371:32-41.

43. Brunzell JD, Hazzard WR, Porte D Jr, Bierman EL. Evidence for a common saturable triglyceride removal mechanism for chylomicrons and very low density lipoprotein in man. J Clin Invest. 1973;52:1578-85.

44. Christian JB, Arondekar B, Boysman EK, et al. Determining triglyceride reductions needed for clinical impact in sever hypertriglyceridemia. Am J Med. 2014;127:36-44.

45. Blaha MJ, Blumenthal RS, Brinton EA, Jacobson TA. National Lipid Association Taskforce on Non-HDL Cholesterol. The importance of non-HDL cholesterol in reporting in lipid management. J Clin Lipidol. 2008;2:267-73.

46. Mora S, Buring J, Ridker PM. Discordance of low-density lipoprotein (LDL) cholesterol with alternative LDL-related measures and future coronary events. Circulation. 2014;129:553-61.

47. Ballantyne CM, Olsson AG, Cook TJ, Mercuri MF, Pedersen TR, Kjekshus J. Influence of low high-density lipoprotein cholesterol and elevated triglyceride on coronary heart disease events and response to simvastatin therapy in $4 \mathrm{~S}$. Circulation. 2001;104:3046-51. 
48. Frick MH, Elo O, Haapa K, et al. Helsinki Heart Study: primary-prevention trial with gemfibrozil in middle-aged men with dyslipidemia. Safety of treatment, changes in risk factors, and incidence of coronary heart disease. $\mathrm{N}$ Engl $\mathrm{J}$ Med. 1987;317:1237-45.

49. Rubins HB, Robins SJ, Collins D, et al. Gemfibrozil for the secondary prevention of coronary heart disease in men with low levels of high-density lipoprotein cholesterol. Veterans Affairs High-Density Lipoprotein Cholesterol Intervention Trial Study Group. N Engl J Med. 1999;341:410-8.

50. Manninen V, Tenkanen L, Koskinen P, et al. Joint effects of serum triglyceride and LDL cholesterol and HDL cholesterol concentrations on coronary heart disease risk in the Helsinki Heart Study. Implications for treatment. Circulation. 1992;85:37-45.

51. Robins SJ, Collins D, Wittes JT, et al. Relation of gemfibrozil treatment and lipid levels with major coronary events: VA-HIT: a randomized controlled trial. JAMA. 2001;285:1585-91.

52. Keech A, Simes RJ, Barter P, et al. Effects of long-term fenofibrate therapy on cardiovascular events in 9795 people with type 2 diabetes mellitus (the FIELD study): randomised controlled trial. Lancet. 2005;366:1849-61.

53. ACCORD Study Group, Ginsberg HN, Elam MB, et al. Effects of combination lipid therapy in type 2 diabetes mellitus. N Engl J Med. 2010;362:1563-74.

54. Scott R, O'Brien R, Fulcher G, et al. Effects of fenofibrate treatment on cardiovascular disease risk in 9,795 individuals with type 2 diabetes and various components of the metabolic syndrome: the Fenofibrate Intervention and Event Lowering in Diabetes (FIELD) study. Diabetes Care. 2009;32:493-8.

55. Boden WE, Probstfield JL, Anderson T, et al. Niacin in patients with low HDL cholesterol levels receiving intensive statin therapy. $\mathrm{N}$ Engl J Med. 2011;365:2255-67.

56. Landray MJ, Haynes R, Hopewell JC, et al. Effects of extended-release niacin with laropiprant in high-risk patients. N Engl J Med. 2014;371:203-12.

57. Guyton JR, Slee AE, Anderson T, et al. Relationship of lipoproteins to cardiovascular events: the AIM-HIGH Trial (Atherothrombosis Intervention in Metabolic Syndrome with Low HDL/High Triglycerides and Impact on Global Health Outcomes). J Am Coll Cardiol. 2013;62:1580-4.

58. Yokoyama M, Origasa H, Matsuzaki M, et al. Effects of eicosapentaenoic acid on major coronary events in hypercholesterolaemic patients (JELIS): a randomised open-label, blinded endpoint analysis. Lancet. 2007;369:1090-8.

59. Saito Y, Yokoyama M, Origasa H, et al. Effects of EPA on coronary artery disease in hypercholesterolemic patients with multiple risk factors: sub-analysis of primary prevention cases from the Japan EPA Lipid Intervention Study (JELIS). Atherosclerosis. 2008;200:135-40.

60. Clinicaltrials.gov. A Study of AMR101 to Evaluate Its Ability to Reduce Cardiovascular Events in High Risk Patients With Hypertriglyceridemia and on Statin. The Primary Objective is to Evaluate the Effect of $4 \mathrm{~g} /$ Day AMR101 for Preventing the Occurrence of a First Major Cardiovascular Event. (REDUCE-IT). Available from: https://clinicaltrials.gov/ct2/show/ NCT01492361. Accessed April 29, 2016.

61. Clinicaltrials.gov. Outcomes Study to Assess STatin Residual Risk Reduction With EpaNova in HiGh CV Risk PatienTs With Hypertriglyceridemia (STRENGTH). Available from: https://clinicaltrials. gov/ct2/show/NCT02104817. Accessed April 29, 2016.

62. Zargar A, Ito MK. Long chain omega-3 dietary supplements: a review of the National Library of Medicine Herbal Supplement Database. Metab Syndrom Related Dis. 2011;9:255-71.

63. Amarin Corporation. Vascepa prescibing information. Available from: http://www.vascepa. com/full-prescribing-information.pdf. Accessed April 29, 2016.

64. GlaxoSmithKline. Lovaza prescribing information. Available from: https://www.gsksource.com/ gskprm/htdocs/documents/LOVAZA-PI-PIL.PDF. Accessed April 29, 2016.

65. Trygg Pharma. Omtryg prescribing information. Available from: http://www.accessdata.fda.gov/ drugsatfda_docs/label/2014/204977s000lbl.pdf. Accessed April 29, 2016.

66. AstraZeneca. Epanova prescribing information. Available from: http://www1.astrazeneca-us.com/ pi/epanova.pdf. Accessed April 29, 2016.

67. Bays HE, Tighe AP, Sadovsky R, Davidson MH. Prescription omega-3 fatty acids and their lipid effects: physiologic mechanisms of action and clinical implications. Expert Rev Cardiovasc Ther. 2008;6:391-409.

68. Le Jossic-Corcos C, Gonthier C, Zaghini I, Logette E, Shechter I, Bournot P. Hepatic farnesyl diphosphate synthase expression is suppressed by polyunsaturated fatty acids. Biochem J. 2005;385:787-94. 
69. Horton JD, Bashmakov Y, Shimomura I, Shimano $\mathrm{H}$. Regulation of sterol regulatory element binding proteins in livers of fasted and refed mice. Proc. Natl Acad Sci USA. 1998;95:5987-5992.

70. Park Y, Harris WS. Omega-3 fatty acid supplementation accelerates chylomicron triglyceride clearance. J Lipid Res. 2003;44:455-63.

71. Harris WS, Bulchandani D. Why do omega-3 fatty acids lower serum triglycerides? Curr Opin Lipidol. 2006;17:387-93.

72. Khan S, Minihane AM, Talmud PJ, et al. Dietary long-chain n-3 PUFAs increase LPL gene expression in adipose tissue of subjects with an atherogenic lipoprotein phenotype. J Lipid Res. 2002;43:979-85.

73. Reiffel JA, McDonald A. Antiarrhythmic effects of omega-3 fatty acids. Am J Cardiol. 2006;98:50i-60i.

74. Robinson JG, Stone NJ. Antiatherosclerotic and antithrombotic effects of omega-3 fatty acids. Am J Cardiol. 2006;98:39i-49i.

75. Mori TA, Beilin LJ. Omega-3 fatty acids and inflammation. Curr Atheroscler Rep. 2004;6:461-7.

76. Wang Q, Liang X, Wang L, et al. Effect of omega-3 fatty acids supplementation on endothelial function: a meta-analysis of randomized controlled trials. Atherosclerosis. 2012;221:536-43.

77. Vandongen R, Mori TA, Burke V, Beilin LJ, Morris J, Ritchie J. Effects on blood pressure of omega 3 fats in subjects at increased risk of cardiovascular disease. Hypertension. 1993;22:371-9.

78. Wei MY, Jacobson TA. Effects of eicosapentaenoic acid versus docosahexaenoic acid on serum lipids: a systematic review and meta-analysis. Curr Atheroscler Rep. 2011;13:474-83.

79. Morton A, Furtado J, Amerine W, Kling D, Davidson M, Sacks F. The effect of omega-3 carboxylic acids on apolipoprotein CIII containing lipoproteins in moderate to severe hypertriglyceridemia. Circulation. 2014;130(Suppl 1):A16864.

80. Harris WS, Ginsberg HN, Arunakul N, et al. Safety and efficacy of Omacor in severe hypertriglyceridemia. J Cardiovasc Risk. 1997;4:385-91.

81. Pownall HJ, Brauchi D, Kilinc C, et al. Correlation of serum triglyceride and its reduction by omega-3 fatty acids with lipid transfer activity and the neutral lipid compositions of high-density and low-density lipoproteins. Atherosclerosis. 1999;143:285-97.

82. Davidson MH, Stein EA, Bays HE, et al. Efficacy and tolerability of adding prescription omega-3 fatty acids $4 \mathrm{~g} / \mathrm{d}$ to simvastatin $40 \mathrm{mg} / \mathrm{d}$ in hypertriglyceridemic patients: an 8-week, randomized, double-blind, placebo-controlled study. Clin Ther. 2007;29:1354-67.

83. Bays HE, Ballantyne CM, Kastelein JJ, Isaacsohn JL, Braeckman RA, Soni PN. Eicosapentaenoic acid ethyl ester (AMR101) therapy in patients with very high triglyceride levels (from the Multi-center, plAcebo-controlled, Randomized, double-blINd, 12-week study with an open-label Extension [MARINE] trial). Am J Cardiol. 2011;108:682-90.

84. Ballantyne CM, Bays HE, Kastelein JJ, et al. Efficacy and safety of eicosapentaenoic acid ethyl ester (AMR101) therapy in statin-treated patients with persistent high triglycerides (from the ANCHOR study). Am J Cardiol. 2012;110:984-92.

85. Kastelein JJ, Maki KC, Susekov A, et al. Omega-3 free fatty acids for the treatment of severe hypertriglyceridemia: the EpanoVa fOr Lowering Very high triglyceridEs (EVOLVE) trial. J Clin Lipidol. 2014;8:94-106.

86. Maki KC, Orloff DG, Nicholls SJ, et al. A highly bioavailable omega-3 free fatty acid formulation improves the cardiovascular risk profile in high-risk, statin-treated patients with residual hypertriglyceridemia (the ESPRIT trial). Clin Ther. 2013;35:1400-11.

87. Tsujita T, Okuda H. The synthesis of fatty acid ethyl ester by carboxylester lipase. Eur J Biochem. 1994;224:57-62.

88. Beckermann B, Beneke M. Seitz I [Comparative bioavailability of eicosapentaenoic acid and docasahexaenoic acid from triglycerides, free fatty acids and ethyl esters in volunteers]. Arzneimittelforschung. 1990;40:700-4.

89. Davidson MH, Johnson J, Rooney MW, Kyle ML, Kling DF. A novel omega-3 free fatty acid formulation has dramatically improved bioavailability during a low-fat diet compared with omega-3-acid ethyl esters: the ECLIPSE (Epanova $^{\circledR}$ compared to Lovaza $^{\circledR}$ in a pharmacokinetic single-dose evaluation) study. J Clin Lipidol. 2012;6:573-84.

90. Maki KC, Keane WF, Bouhajib M, Pop R, Bobotas G. Pharmacokinetics of MAT9001, an omega-3 fatty acid medication, compared with eicosapentaenoic acid ethyl esters in hypertriglyceridemic subjects. FASEB. 2016;30(S1198):7.

91. Albert BB, Derraik JG, Cameron-Smith D, et al. Fish oil supplements in New Zealand are highly oxidised and do not meet label content of n-3 PUFA. Sci Rep. 2015;5:7928. 